Article

\title{
Determination of Mohr-Coulomb Parameters for Modelling of Concrete
}

\author{
Selimir Lelovic ${ }^{1, *}$ and Dejan Vasovic ${ }^{2, *}$ \\ 1 Faculty of Civil Engineering, University of Belgrade, 11000 Belgrade, Serbia \\ 2 Faculty of Architecture, University of Belgrade, 11000 Belgrade, Serbia \\ * Correspondence: lelovic@grf.bg.ac.rs (S.L.); d.vasovic@arh.bg.ac.rs (D.V.)
}

Received: 23 July 2020; Accepted: 7 September 2020; Published: 13 September 2020

\begin{abstract}
Cohesion is defined as the shear strength of material when compressive stress is zero. This article presents a new method for the experimental determination of cohesion at pre-set angles of shear deformation. Specially designed moulds are created to force deformation (close to $\tau$-axis) at fixed pre-set values of angle with respect to normal stress $\sigma$. Testing is performed on series of concrete blocks of different strengths. From the compressive side, cohesion is determined from the extrapolation of the linear Mohr-Coulomb (MC) model, as the intercept on the shear stress axis. From the tensile stress side (from the left), cohesion is obtained using the Brazilian test results: first, indirect tensile strength of material $\sigma_{t}{ }^{\mathrm{BT}}$ is measured, then Mohr circle diagram values are calculated and cohesion is determined as the value of shear stress $\tau^{\mathrm{BT}}$ on the Mohr circle where normal stress $(\sigma) t=0$. A hypothesis is made that cohesion is the common point between two tests. In the numerical part, a theory of ultimate load is applied to model Brazilian test using the angle of shear friction from the MC model. Matching experimental and numerical results confirm that the proposed procedure is applicable in numerical analysis.
\end{abstract}

Keywords: cohesion; angle of shear deformation; Mohr-Coulomb model; induced tensile strength; concrete samples; Brazilian test; finite element method (FEM)

\section{Introduction}

In order to describe the deformation behaviour of brittle material, complex issues are discussed for the Brazilian test and forced shear test. The control of many variables connected with various samples and testing equipment is a difficult and expensive task aimed to obtain representative stress strain curves for real material. Concrete, as a brittle material, is inhomogeneous, its mechanical properties vary even within the same batch, and therefore, the number of measurements must follow any definition of the material properties where the statistical distribution of the experimental results is performed. Many authors obtained close mathematical description for the complex deformation behaviour of a real material in some cases for a specific test [1]. However, the same mathematical model may not be valid in describing the deformation behaviour under a different set of experimental conditions.

It is widely known that ordinary concrete is a non-homogeneous mixture of Portland cement, aggregate (gravel and sand), water, and different admixtures. The hardening of concrete is a continuous and long-lasting process and the compressive strength of the concrete, being the most used and most important characteristic of the concrete, is standardised as compressive strength at the age of 28 days. Mechanical properties of concrete may be described as those of brittle ceramic material. It is widely known that concrete is an anisotropic material and has high compressive and low tensile strength [2]. Therefore, in structural applications, concrete is used as a material mostly subjected to compression [3]. With the increase of the load, concrete exhibits the following behaviour: elastic deformation and plastic flow in early stages [4], followed by the appearance and propagation of microcracks [5]. 
In the Brazilian test (split cylinder test), compression induces tension. Therefore, in modelling such tests, compression may be described with the mechanics of plastic deformation, while induced reactive tension may be described with fracture mechanics [6]. The plastic behaviour of concrete was modelled either as elastic-perfectly plastic material [7] or as elastic-plastic material with strain hardening [8]. Various authors used a large number of different techniques to investigate the microstructure of concrete, in order to explain plain concrete behaviour, such as SEM [9], various synchrotron radiation techniques to characterise cement-based material [10], non-destructive techniques (such as X-ray tomography and ultrasonic imaging) to visualise inclusions in concrete samples [11] and CT scanning for density profiles' air pockets distribution [12].

Bazant et al. [13] attempted to estimate the cumulative probability of the concrete sample fail under a given load. To describe the size effect of cracks in a brittle material, they used the Weibull statistical model. The paper presented an attempt to combine the reliability theory with fracture mechanics. There were two phases perceived synergistically: first, crack initiation phase, statistically calculated (according to the reliability theory), and second, crack propagation phase, calculated as the energy part (described as fracture nonlinearity).

Some authors tried to understand where the initial microcracks form, by applying moderate external load to induce microcracks, which formed at the interface between the cement paste and coarse gravel particles [14]. It is noted that increased load induced the coalescence of the microcracks into the large macro-cracks.

Kansan and Jirsa [15] indicated that, for the elements subjected to uni-axial compression, as a function of axial deformation, plastic hardening occurs first, followed by plastic softening. Chen [16] justified the assumption that concrete can be considered as perfectly plastic material applicable for certain classes of problems in mechanics. He described the argument as an "idealisation which contains the essential features of certain material behaviour: the tangent modulus when loading in the plastic range is small compared with the elastic modulus, and the unloading response is elastic. Further, the strain level of interest in a problem determines the choice of flow stress. Thus, in a sense, this perfectly plastic flow stress somewhat represents an averaging work-hardening or work-softening of the material over the field of flow". Further illustrations of the above can be found in the literature [17,18].

In a classic paper, the relationship between compressive and tensile strength [19] is reported on rocks. Linear fit correlation indicated that one single factor might be of a prime importance in the fracture process. A suggested factor is the presence of microcracks, which are inherent in most rock types. In another report, a two-parameters parabolic Mohr criterion model is developed to analyse the failure modes of rock materials using Brazilian test results [20]. The first parameter is called materials strength expressed as the ratio $m=\sigma_{t} / \sigma_{c}$ and the second parameter is $N=(m+2-2 \sqrt{m+a}) \cdot \sigma_{t}$. Four failure modes are defined as combination of tensile and shear stress: pure tensile failure, shear damage, pure shear failure and shear failure under compression. Failure modes, as presented in the paper by Ma et al. [21], are classified into five categories: tensile failure across and along the weakness planes, shear failure across and along the weakness planes, and mixed failure.

In a similar paper, cohesion and angle of friction are determined from tensile strength and uniaxial compression [22]. Presented are empirical equations which correlate compressive strength $\left(\sigma_{\mathrm{c}}\right)$, tensile strength $\left(\sigma_{t}\right)$, and cohesion (c). For example, $1 / \mathrm{m}$ parameter looked as the ratio of $\sigma_{\mathrm{t}} / \sigma_{\mathrm{c}}$ is expected to lie in the range from $1 / 5$ to $1 / 20$, with an average value of about $1 / 10$. Test results of compressive strength, and tensile strength for lightly cemented sand ( $54 \%$ of cement) showed $1 / \mathrm{m}$ to be about $1 / 10$. This paper is based on the referenced article by Piratheepan et al. [23], where cohesion and friction angle are derived from first principles to be as follows:

$$
c=\frac{\sigma_{c} \cdot \sigma_{t}}{2 \sqrt{\sigma_{t} \cdot\left(\sigma_{c}-2 \sigma_{t}\right)}}, \phi=\sin ^{-1}\left(\frac{\sigma_{c}-4 \sigma_{t}}{\sigma_{c}-2 \sigma_{t}}\right)
$$


Results obtained in the experimental testing of 35 sets of rock specimens, for the predicted value of cohesion, appear to be more realistic than for the predicted friction angle values. Using linear fit approximation, the following equation is obtained for cohesion: $c=1.82 \cdot \sigma_{t}$ with correlation factor $\mathrm{R} 2=0.92$. Fitting scatter is attributed to heterogeneity in the rock specimens and anisotropy.

Some authors noticed the importance of determining the value of cohesion in order to apply the Mohr-Coulomb model to different types of concrete and used cohesion parameters to describe the concrete softening/hardening and accumulative plastic deformations [24-27].

\subsection{Brazilian Test}

The Brazilian test is described in terms of the contact angle between specimen and loading plates [28]. The contact angle may affect the shear deformation in a region just under the loading plates, while tensile stress plays a major role in the centre of the specimen. According to the standard ASTM D 3967-08, the tensile strength equation is [29]

$$
\sigma_{\mathrm{t}}^{\mathrm{BT}}=\frac{2 \cdot \mathrm{P}_{\max }}{\pi \cdot \mathrm{D} \cdot \mathrm{B}}
$$

where Pmax is the ultimate load reached during the test, $\mathrm{D}$ is the diameter and $\mathrm{B}$ is the sample thickness. As pointed out in the literature [30], it is possible that shear stresses in the contact region reach critical magnitude and create initial cracks long before the tensile stresses reach their limit in the centre. In such cases, the most likely place of splitting a disk in the Brazilian test is not diametrical but is on surfaces indicated with border lines of the loading area.

The Brazilian test is looked at as the tensile stress, but in reality, it is a more complex stress state. In this paper, it is proposed to look at the Brazilian complex stress state as if it were composed of pure shear and uniaxial compression. The proposed model is based on illustration reported by Hobbs for the Brazilian test, in which shear stress state is in the sample region just under the loading plates. Figure 1 shows block diagrams with the proposed stress state for the Brazilian test for massive rocks, as composed of pure shear $\left(\tau=\sigma_{t}\right)$ and added uniaxial compression of $\sigma \mathrm{c}=2 \sigma_{\mathrm{t}}$. The radius for the Mohr circle for pure shear segment is $R 1=\tau=\sigma_{t}$ and radius for the Mohr circle of the added compression is $\mathrm{R} 2=\sigma_{\mathrm{c}}=\sigma_{\mathrm{t}}$, making the total radius for the Mohr circle for the Brazilian test for rocks to be $R=R 1+R 2=2 \sigma_{t}$, as shown in Figure $1 b$.

The strain distribution of the Brazilian specimen and transition between shear and tensile failure modes is reported in the paper by Li et al. [31]. A numerical analysis described in this paper showed that the maximum tensile stress and strain occurs about $5 \mathrm{~mm}$ away from the loading points along the central loading diameter of the 50-mm diameter Brazilian disc. This location corresponds to a failure mode transition between shear and tensile failure, as shown in Figure 1c; illustration reported by Hobbs.

A recently published paper showed a new interesting practical test method for determination of cohesion values of rock materials using double shear jaws [32]. Steel jaws are designed and manufactured for testing rock materials. Effects of various testing parameters are reported with respect to induced shear stress failure mechanisms.

Previous standard method of testing the shear strength for intact rock mass [33] is carried out in special moulds, which enable shear at the desired angle $\alpha$. Angles at which testing is performed are $30^{\circ}, 45^{\circ}$ and $70^{\circ}$ with respect to normal stress. However, from the practical point of view, it is extremely difficult to properly measure samples at $30^{\circ}$. We made several attempts to test rock samples, but attempts were not successful: many samples crushed before being tested, either on the edges or any rough surfaces or planes, at very high values of applied loads. It was decided to avoid the region of testing over $45^{\circ}$ with respect to normal stress, and to stay close to the shear stress axis. 


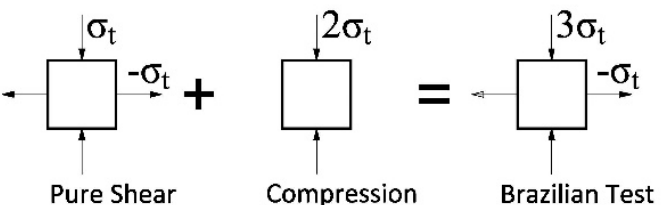

(a)

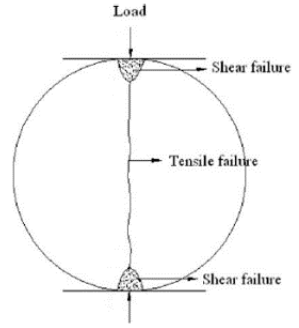

(c)

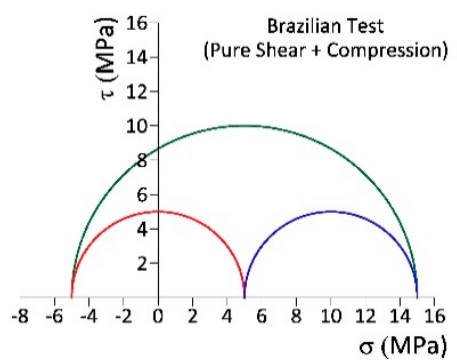

(b)

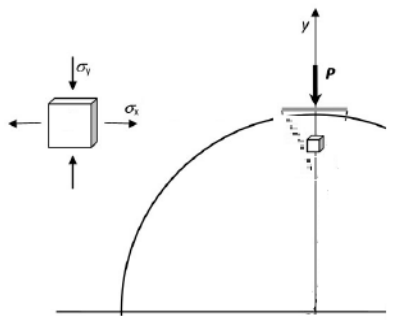

(d)

Figure 1. (a) Block diagram showing Brazilian test as composed of pure shear with the radius of $\tau=\sigma_{\mathrm{t}}$ and uniaxial compression of $\sigma_{\mathrm{c}}=2 \sigma_{\mathrm{t}} ;(\mathbf{b})$ Mohr circles showing the Brazilian test (blue circle), pure shear with the radius of $\tau=\sigma_{t}$ (red circle) and uniaxial compression of $\sigma_{\mathrm{c}}=2 \sigma_{\mathrm{t}}$ (green circle). (c) Transition between shear and tensile failure modes in a solid disk in the Brazilian test (as illustrated by Hobbs). (d) Block diagram showing the state of shear stress under loading plates.

\subsection{Shear Test at Pre-Set Angles}

The novelty of this proposed new method is to stay close to $\tau$-axis, to force shear deformation at $80^{\circ}$ and $70^{\circ}$ with respect to normal stress $\sigma$-axis. It is a simple, efficient procedure for the application of large size samples of inhomogeneous materials, such as rocks and concrete blocks. The relation between experimental measurements and parameters such as cohesion and the angle of friction is straightforward. As indicated in Figure 2, cohesion is obtained by extrapolation of the linear fit points to obtain intercept with shear stress axis, and the angle of friction is obtained from the linear fit slope.
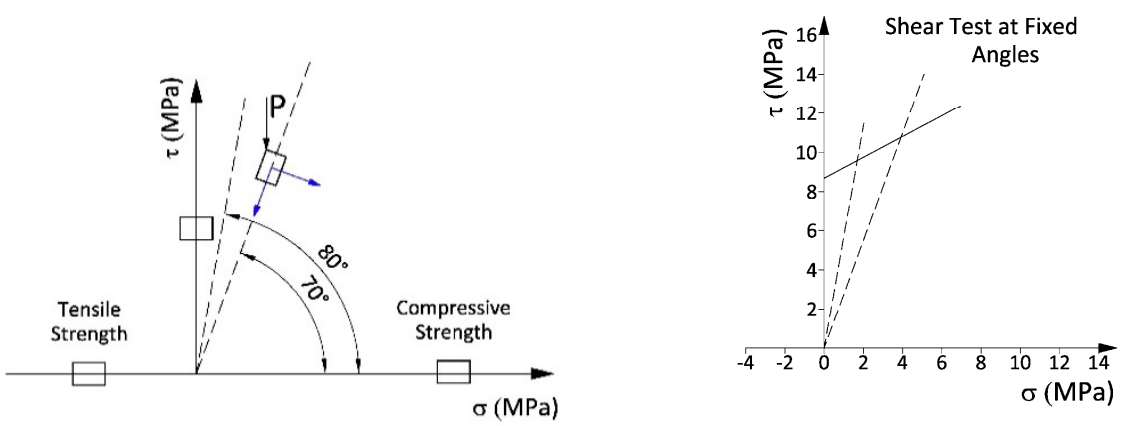

Figure 2. Schematic drawing showing shear test at fixed angles with respect to normal stresses $(\sigma)$, in order to obtain points for linear Mohr-Coulomb (MC) model.

A presented method for determining shear strength limit in rock mechanics is based on Yugoslavian standard JUS B7.130 reference [34], with the idea that, for brittle material, it is possible to hold the angle of shear deformation constant while applying load. New testing moulds were created with angles at which testing is to be carried out close to the shear stress axis, chosen to be at fixed angles of $80^{\circ}$ and $70^{\circ}$ with respect to normal stress, as indicated in Figure 3. 

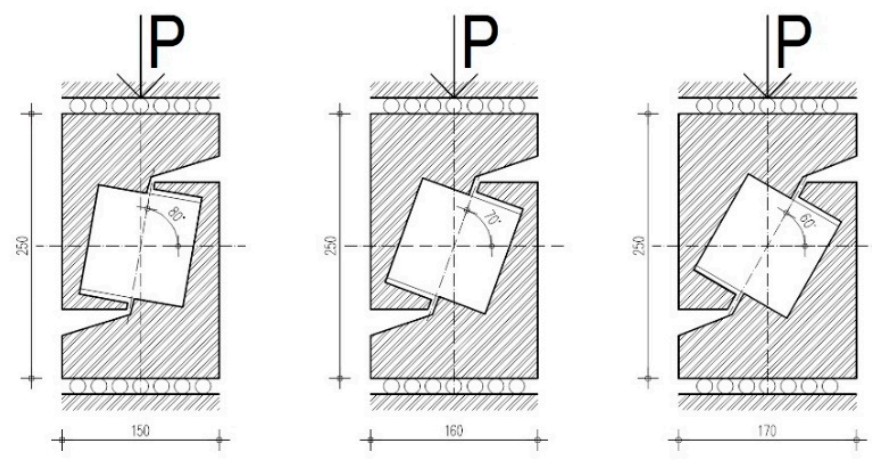

(a)

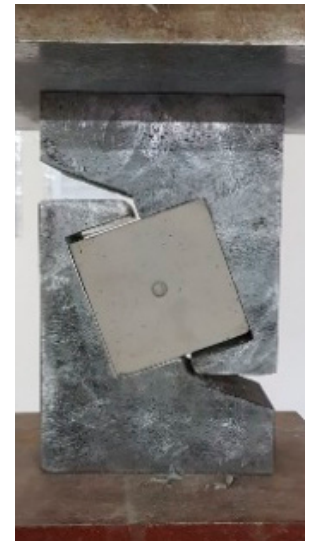

(b)

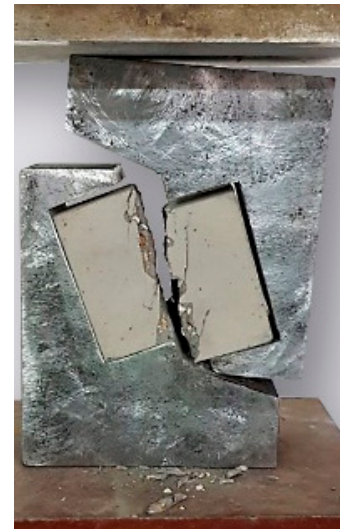

(c)

Figure 3. Experimental setup for shear strength testing: (a) schematic drawings of mould; (b) photo of experimental setup in the laboratory; (c) photo of failed sample.

The following equations are used to describe normal and shear stress

$$
\begin{gathered}
\sigma=P \cdot \cos \alpha / A \\
\tau=P \cdot \sin \alpha / A
\end{gathered}
$$

where $\mathrm{P}$ is the failure force, $\mathrm{A}$ is the surface and $\alpha$ is the angle wrt to $\sigma$.

\section{Materials and Testing}

In order to define parameters of different types of concrete, several test batches with different mixture proportions were performed according to EN 206-1. As a binder, cement type CEM I 42,5 R (Lafarge BFC, Serbia, according to EN 197-1:2000) was used. In order to test the influence of aggregate type on concrete parameters, two different types of aggregate were used: concrete type A with crushed andesite aggregate from "Šumnik" quarry in Raška, Serbia, and concrete type M with natural river aggregate from river Morava, Serbia. Third concrete type mixture (Mohr-Coulomb (MC)) was prepared with natural river aggregate and addition of styrene-butadiene latex. Polycarboxylate superplasticising admixture (PCA) were added to some mixtures in order to achieve predicted strength and designed Abrams' cone slump of 18-20 cm. Table 1 shows mixture proportions of different concrete batches.

Concrete was casted in $15 \mathrm{~cm}$ cubic moulds. All the mixtures were casted in series of 6 samples: 3 for compressive strength testing (EN 12390-2), and 3 for indirect tensile strength (Brazilian test-EN 12390-6). Testing was performed in the Laboratory for Material Testing at the University of Belgrade, Faculty of Civil Engineering. Testing equipment used for this experiment is AMSLER hydraulic load frame, max. capacity of $2500 \mathrm{kN}$, equipped with two inductive sensors (LVDT) calibrated to 
1 micron resolution (Schaffhausen, Swicerland). After 28 days, samples were tested on the hydraulic compression frame of the 200-tons $(2000 \mathrm{kN})$ capacity, synchronised with two inductive sensors (LVDT) calibrated to 1-micron resolution. Those sensors provide automatic acquisition of data with capacity of 20 to 40 data points per second. The results of the concrete samples are shown in Table 2.

Table 1. Mixture proportion of different concrete batches.

\begin{tabular}{lcccccccc}
\hline \multicolumn{1}{c}{ Concrete Mixture $\left(\mathbf{k g}\right.$ per $\mathbf{~ m}^{\mathbf{3}}$ ) } & \multicolumn{3}{c}{ Type A } & \multicolumn{3}{c}{ Type M } & \multicolumn{3}{c}{ Type MC } \\
\hline Aggregate & \multicolumn{3}{c}{ crushed andesite } & \multicolumn{3}{c}{ natural river } & \multicolumn{2}{c}{ natural river } \\
& A1 & A2 & A3 & M1 & M2 & M3 & MC1 & MC2 \\
0-4 mm (45\%) & 860 & 845 & 825 & 870 & 845 & 830 & 835 & 820 \\
4-8 mm (16\%) & 305 & 300 & 290 & 310 & 300 & 295 & 300 & 290 \\
8-16 mm (39\%) & 750 & 735 & 715 & 755 & 730 & 720 & 725 & 710 \\
Cement: CEM I 42,5 R & 320 & 370 & 420 & 300 & 350 & 400 & 360 & 400 \\
Water & 160 & 148 & 147 & 165 & 175 & 152 & 180 & 160 \\
PCA Superplasticizer & 1.92 & 2.96 & 4.2 & - & - & 3.2 & - & 3.2 \\
SB Latex (50\% dry solid content) & - & - & - & - & - & - & 18 & 20 \\
\hline
\end{tabular}

Table 2. Compressive and indirect tensile strength for concrete types A, M and MC after 28 days.

\begin{tabular}{ccccccccc}
\hline Concrete Type & \multicolumn{3}{c}{ Compressive Strength (MPa) } & \multicolumn{3}{c}{ Indirect Tensile Strength (MPa) } \\
\hline sample & 1 & 2 & 3 & Ave. & 4 & 5 & 6 & Ave. \\
A1 & 43.70 & 44.38 & 39.62 & 42.57 & 3.71 & 3.16 & 3.48 & 3.45 \\
A2 & 71.11 & 77.24 & 72.93 & 73.76 & 4.24 & 4.21 & 4.73 & 4.39 \\
A3 & 86.36 & 87.73 & 82.00 & 85.36 & 5.10 & 5.89 & 5.69 & 5.56 \\
M1 & 31.25 & 30.92 & 32.52 & 31.56 & 3.11 & 2.92 & 3.30 & 3.11 \\
M2 & 48.67 & 50.06 & 45.20 & 47.98 & 2.77 & 2.97 & 3.30 & 3.01 \\
M3 & 68.44 & 66.89 & 68.70 & 68.01 & 5.12 & 4.90 & 5.36 & 5.13 \\
MC1 & 37.87 & 41.24 & 41.33 & 40.15 & 3.05 & 2.78 & 3.28 & 3.04 \\
MC2 & 64.49 & 59.60 & 64.76 & 62.95 & 4.65 & 4.38 & 4.54 & 4.52 \\
\hline
\end{tabular}

Two additional series of concrete cube samples were designed and casted, in order to provide input data for determination of MC parameters for concrete modelling. Concrete mixtures were designed to represent the concrete of nominal compressive strength of around $30 \mathrm{MPa}$ (labelled MB 30) and concrete of nominal compressive strength of around $50 \mathrm{MPa}$ (labelled MB 50). Additional concrete mixture as a representative for high strength concrete was designed, casted and labelled MB100. Concrete mixture proportions are shown in Table 3.

Table 3. Mixture proportion of concrete batches labelled as MB30 and MB 50.

\begin{tabular}{lccc}
\hline Concrete Mixture $\mathbf{( k g ~ p e r ~ \mathbf { ~ } ^ { 3 } )}$ & MB 30 & MB 50 & MB 100 \\
\hline \multicolumn{1}{c}{ Aggregate } & natural river & natural river & crushed andesite \\
0-4 mm (44\%) & 840 & 810 & $0-2$ mm: 660 \\
4-8 mm (15\%) & 290 & 290 & $2-4$ mm: 220 \\
8-16 mm (41\%) & 780 & 750 & $4-8$ mm: 620 \\
Cement: CEM I 42,5 R & 320 & 370 & 700 \\
Water & 170 & 180 & 210 \\
PCA Superplasticizer & - & 2.2 & 21 \\
\hline
\end{tabular}

Eighteen $100 \mathrm{~mm}$ concrete cubes were casted of both MB30 and MB 50 mixture: three were used to determine compressive strength (shown in Table 4).

The remaining fifteen concrete cubes were used for tensile and shear stress data, presented in Table 5. Due to omission in casting, two samples of MB30 batch were not appropriate for testing, so thirteen samples were tested. Six samples of MB 100 were casted: two for compressive strength, and four for shear test $\left(70^{\circ}\right.$ and $\left.80^{\circ}\right)$. 
Table 4. Compressive and indirect tensile strength for concrete types MB 30 and MB 50 after 28 days.

\begin{tabular}{ccccc}
\hline Concrete Type & \multicolumn{4}{c}{ Compressive Strength (MPa) } \\
\hline sample & 1 & 2 & 3 & Ave. \\
MB 30 & 35.22 & 36.18 & 34.62 & 35.34 \\
MB 50 & 58.26 & 61.12 & 58.48 & 59.29 \\
MB 100 & 100.2 & 97.7 & - & 99.0 \\
\hline
\end{tabular}

Table 5. Shear test data at fixed angles of $80^{\circ}, 70^{\circ}$ and $60^{\circ}$ with respect to $\sigma$ - axis, and tensile test data for concrete cube samples MB 30 and MB 50.

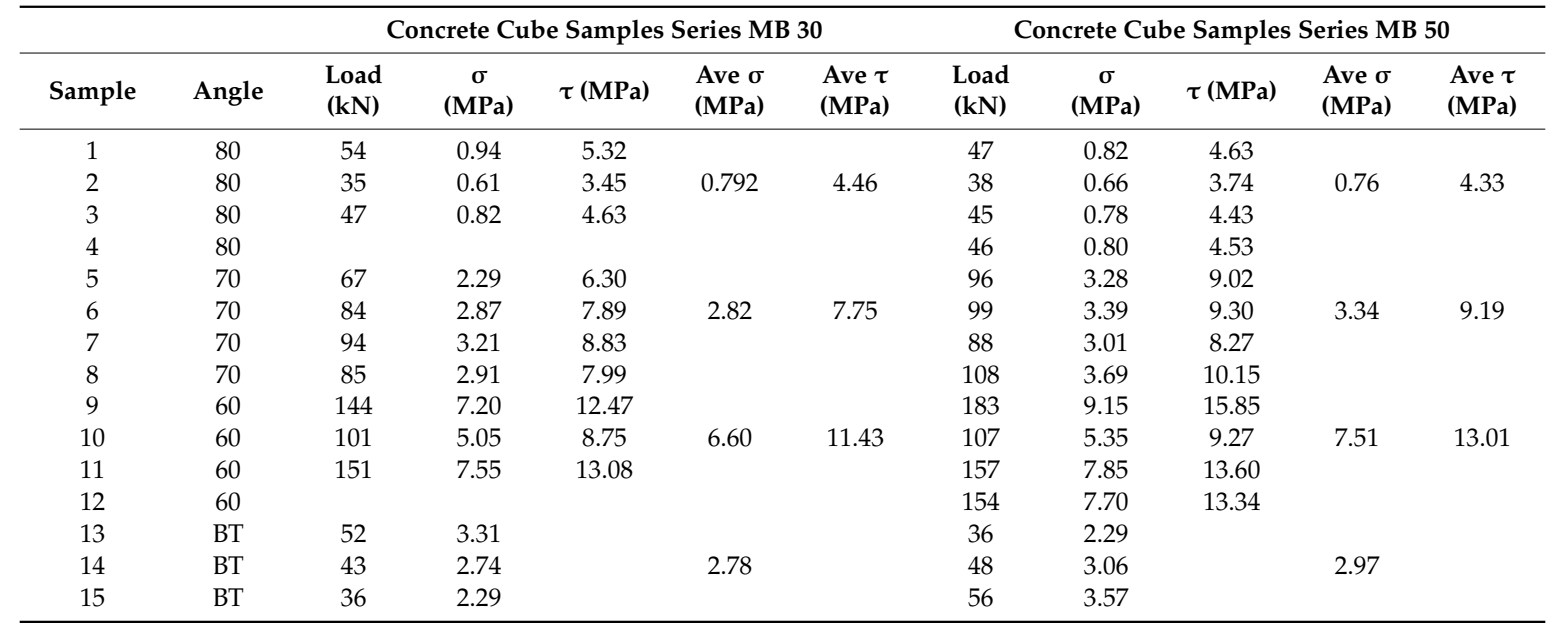

\section{Experimental Data}

Tests of shear strength through mass were carried out on numerous cubic samples. Dimensions of the samples were $100 \times 100 \times 100 \mathrm{~mm}$. With values determined for $\sigma$ and $\tau$, a graph of strength limit state is made, approximated to straight line, whose inclination determines the value of the internal friction angle, and the intersection with ordinate defines the value of cohesion c.

The new shear test method is applied for testing concrete blocks as an example of brittle material. Concrete is a material with complex function of many input variables associated with its components (such as type of cement and aggregate, chemical composition, particle size distribution, etc.) [35]. The tensile strength of most concrete types generally does not exceed $10 \%$ of the corresponding compressive strength [36]. As indicated in the referenced paper by $\mathrm{O}^{\prime} \mathrm{Neil}$, compressive strength for conventional concrete is generally less than $40 \mathrm{MPa}$. Concretes designed with compression strength of 41.4 MPa or greater are known as "high-strength".

In this paper, an attempt is made to create concrete series with designed values for compressive strength, and to determine the dependence of tensile strength, and of cohesion. A series of indirect tensile strength (Brazilian test) was performed on concrete series type A, M, MC, MB30, MB50, MB100. Sets of these tests are shown in the Figure 4.

Table 6 presents the summary of experimental data for concrete series made using different input parameters such as aggregate material. For example, concrete series $\mathrm{M}$ is created using grain aggregate from the Morava river in Serbia. Looking at the data presented for concrete series M1 and M2, compressive strength increased from $31.5 \mathrm{MPa}$ to $48 \mathrm{MPa}$ with no significant change in tensile strength at around $3 \mathrm{MPa}$. Figure 5 shows functional dependence for all samples from Table 6, tensile strength being a function of designed compressive strength. 

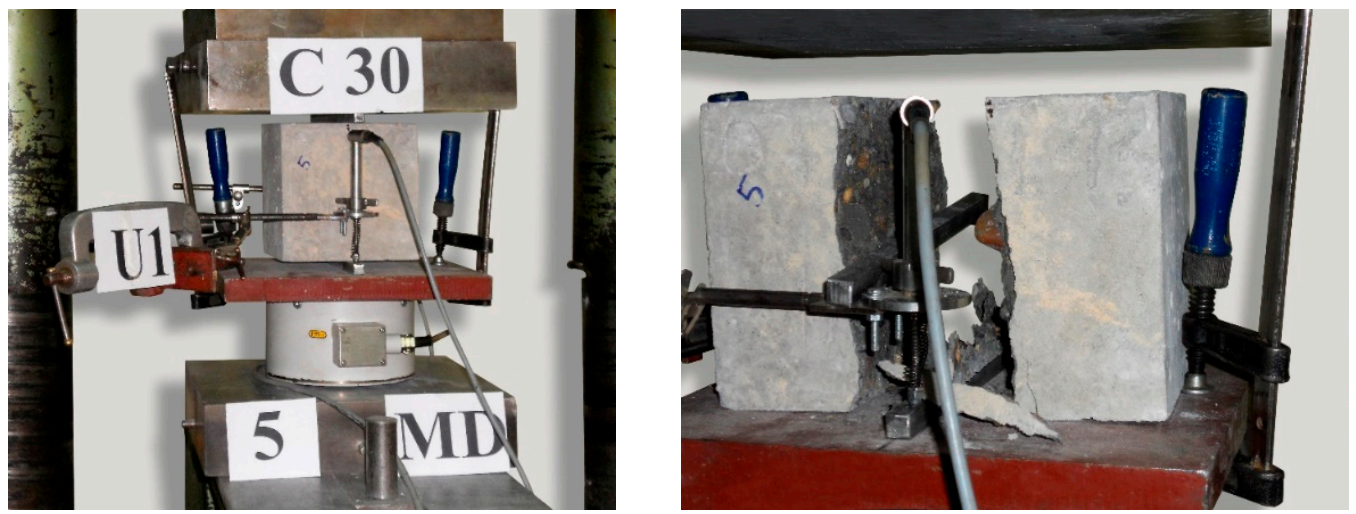

Figure 4. Experimental setup for induced tensile load capacity in a concrete sample.

Table 6. Average compressive and tensile strengths for different concrete series.

\begin{tabular}{ccc}
\hline Concrete Series & Compressive Strength (MPa) & Tensile Strength (MPa) \\
\hline M1 & 31.56 & 3.11 \\
MC1 & 40.15 & 3.04 \\
A1 & 42.60 & 3.45 \\
M2 & 47.97 & 3.01 \\
MC2 & 62.95 & 4.52 \\
M3 & 68.01 & 5.13 \\
A2 & 73.76 & 4.39 \\
A3 & 85.36 & 5.56 \\
\hline
\end{tabular}

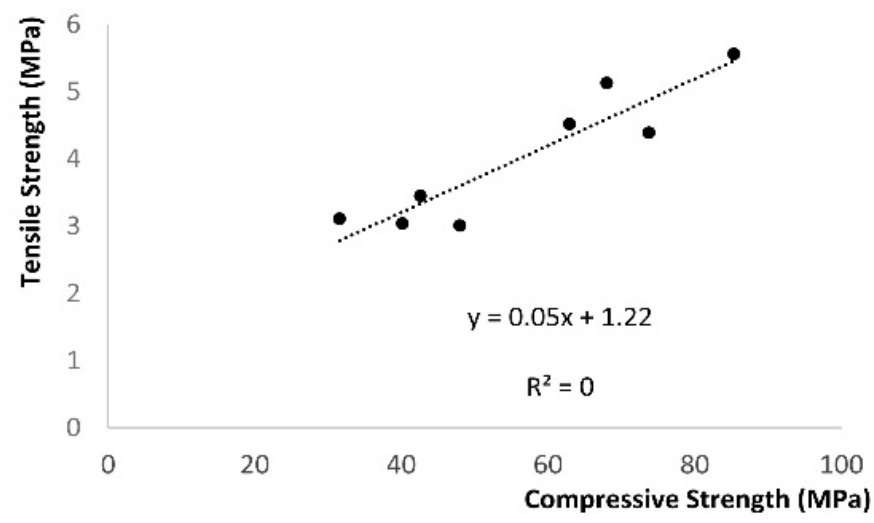

Figure 5. Relationship between compressive and tensile strengths for concrete series presented in Table 1.

The presented linear fit is showing an intercept at $1.22 \mathrm{MPa}$ and a small gain of only 0.05 with a large spread of experimental data indicated with correlation function of only 0.85 . In fact, it is a difficult assignment to create a recipe for concrete series with designed values for both compressive and tensile strengths. As mentioned previously, Hobbs showed linear dependence between compressive and tensile strengths for massive rocks: compressive strength increased four times going from limestone to sandstone (6000 lb/in2/41.37 MPa to 24,000 lb/in2/165.48 MPa), tensile strength increased 3.7 times (2600 lb/in2/17.93 MPa to $9500 \mathrm{lb} / \mathrm{in} 2 / 65.50 \mathrm{MPa})$.

Nevertheless, concrete is a more heterogeneous material in comparison to rocks, with a complex structure, and therefore, the increase in compressive strength does not provoke the increase in tensile strength. Attempts to make a correlation between compressive and tensile strengths for concrete are reported [37,38]. Empirical equations for tensile strength as function of compressive strength ranged from $\sigma_{\mathrm{t}}=0.6 \cdot \sqrt{\sigma_{\mathrm{c}}}$ to $\sigma_{\mathrm{t}}=0.2 \cdot\left(\sigma_{\mathrm{c}}\right)^{0.7}$ while American Concrete Institute Committee reported [39] $\sigma_{\mathrm{t}}=0.59 \cdot \sqrt{\sigma_{\mathrm{c}}}$ in the range for compressive strength between 21 and $83 \mathrm{MPa}$. Further attempts at 
making systematic correlation between compressive strength and tensile strength of ultra-high strength concrete are made on 284 splitting test specimens and 265 flexural test specimens [40]. Test results showed, and a regression analysis carried out on all those samples suggested, new empirical equation for tensile strength of ultra-high strength concrete as function of compressive strength $\sigma_{t}=0.8 \cdot \sqrt{\sigma_{\mathrm{c}}}$.

Two additional series of concrete cube samples are designed and produced, one with a mixture for nominal compressive strength of $30 \mathrm{MPa}$ (designated MB 30) and a second series of concrete cubes with nominal compressive strength of $50 \mathrm{MPa}$ (designated MB 50). Tensile test data and shear stress data are presented in Table 5.As shown in Table 5 and Figure 6, concrete blocks designed with significant increase in compressive strengths from $30 \mathrm{MPa}$ to $50 \mathrm{MPa}$ (67\% increase) showed no significant change in tensile strengths at $3 \mathrm{MPa}$, with cohesion values following trend of tensile strength and staying flat at $4 \mathrm{MPa}$. This means that process parameters, which showed significant effect on compressive strength, did not have an effect on tensile strength and cohesion. The presented results showed a strong argument towards the importance of measuring cohesion directly, to avoid making empirical functional dependence between $\sigma_{\mathrm{c}}$ and $\sigma_{\mathrm{t}}$ and then making a prediction about cohesion.

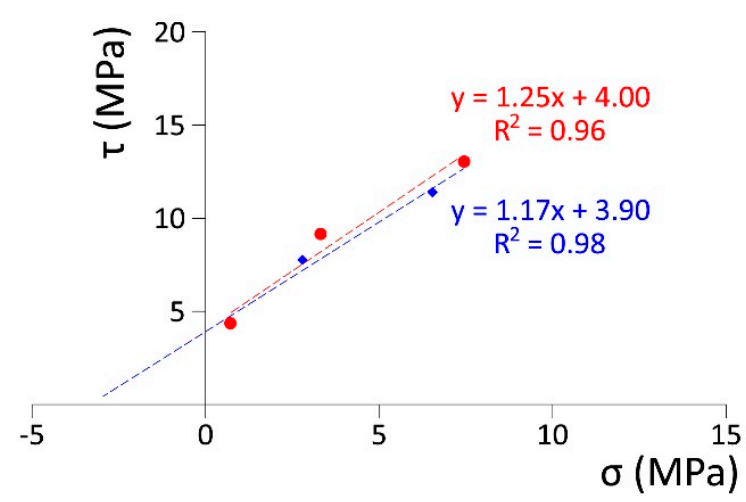

Figure 6. Experimental data points from Table 5 presented in $\sigma-\tau$ space with linear fit to determine cohesion from the Mohr-Coulomb model.

The Mohr circle approach is used to look at functional dependence between tensile strength and cohesion for concrete. Since cohesion is inherent in materials property, it is a common point regardless of whether it is determined from the right side as intercept of the linear fit at $\sigma_{\mathrm{c}}=0$, or from the left side as the value on the Mohr circle at $\sigma_{t}=0$. In this report, proposed is the stress diagram for the Brazilian test for concrete samples, as if it were composed of pure shear with radius $R 1\left(R 1=\tau=\sigma_{t}\right)$ and additional compressive stress with radius $R 2\left(R 2=\sigma_{c}=\sigma_{t} / 3\right)$, as presented in Figure 7 . Therefore, overall radius for the Mohr circle for the Brazilian test for concrete samples is $R=R 1+R 2=\sigma_{t}+\sigma_{t} / 3$.

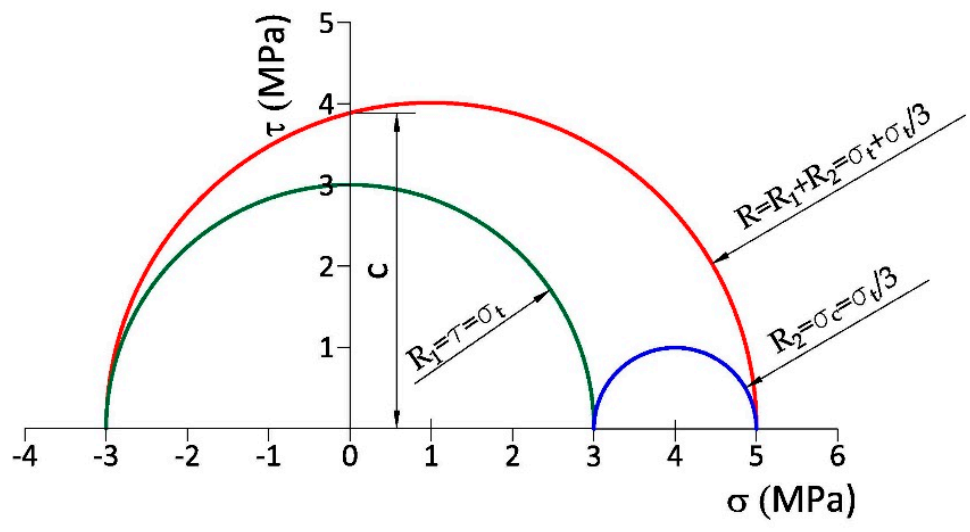

Figure 7. Mohr circle for the Brazilian test of concrete: $\sigma_{\mathrm{t}}=3 \mathrm{MPa}$ and $\mathrm{c}=3.9 \mathrm{MPa}$. 
The calculated Mohr circle showed remarkably good matching with experimental data for concrete series MB-30 and MB-50 $\left(\sigma_{\mathrm{t}}=3 \mathrm{MPa}\right.$ and $\left.\mathrm{c}=3.9 \mathrm{MPa}\right)$. Furthermore, in another example for the very high strength concrete with $100 \mathrm{MPa}$ compressive strength (and in accordance with linear fit presented in Figure 8b), for the tensile strength of $\sigma_{t}=6 \mathrm{MPa}$, the proposed Mohr circle model makes cohesion $\mathrm{c}=7.7 \mathrm{MPa}$. This value is again a very good match with experimental measurements of cohesion at 7.6 MPa, as shown in Figure 8b. Therefore, preliminary observations showed that functional dependence between tensile strength and cohesion for concrete samples as proposed with Mohr circle with radius $R=R 1+R 2=\sigma_{t}+\sigma_{t} / 3$ showed remarkably good match with experimental data for concrete samples, with compressive strengths of $30 \mathrm{MPa}, 50 \mathrm{MPa}$ and $100 \mathrm{MPa}$. Again, it is important to point to the fact that, in this paper, only preliminary observations have been presented, while a more systematic study with increased sample size is needed in order to confirm the proposed correlation between cohesion and tensile strength in concrete.

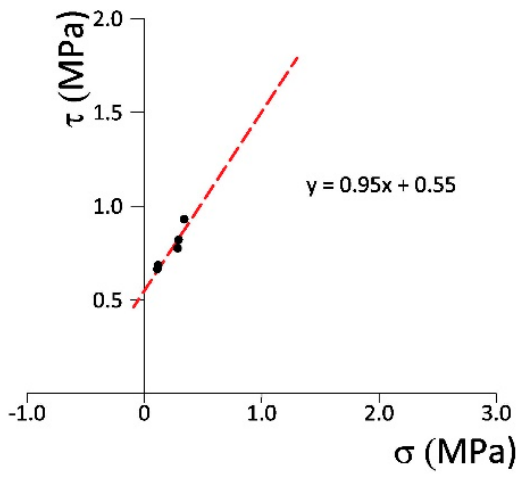

(a)

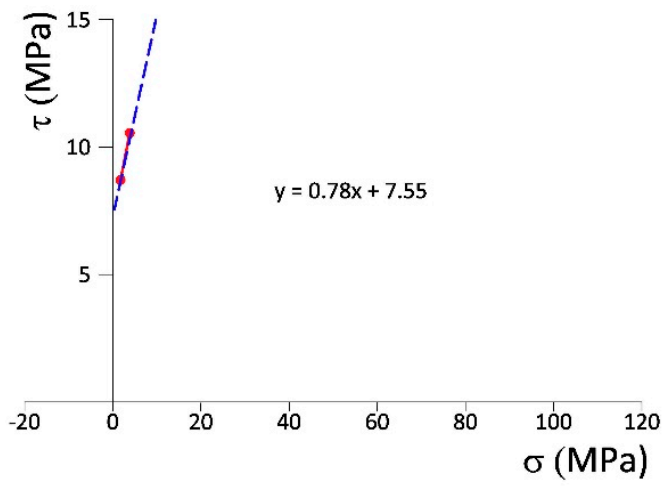

(b)

Figure 8. Experimental data points for (a) Ytong blocks with compression strength of $3 \mathrm{MPa}$ showing cohesion of $0.55 \mathrm{MPa}$ and (b) very high strength concrete blocks with compression strength of $100 \mathrm{MPa}$, showing cohesion of $7.55 \mathrm{MPa}$.

Figure 8 shows that new method is applicable for testing the wide range of materials, such as light concrete blocks, "Ytong" with compressive strength of only $3 \mathrm{MPa}$, to the very high compressive strength concrete of $100 \mathrm{MPa}$. Cohesion value measured for Ytong blocks is $0.55 \mathrm{MPa}$, while cohesion for very high strength concrete blocks is $7.55 \mathrm{MPa}$.

\section{Numerical Modelling}

For homogeneous materials like rocks, angle of internal friction is its inherent materials property. However, angle of internal friction for inhomogeneous materials like plain concrete is not its inherent property, but varies with process parameters. Even within one series, it may vary from batch to batch. As shearing force is greater than cohesive force, microcracks are formed, then angle of internal friction is first related to the resistance to crack propagation between grains and second to shear frictional (SF) resistance of cracked concrete to sliding [41,42]. From the process point of view, friction angle is a complex function of many variables associated with grain particle size, its material structure, chemical composition, anisotropy, porosity, etc.

For the numerical modelling, angle of internal friction is obtained from the bearing capacity model. From the theory of limit analysis (Citovich [43] and Nielsen and Hoang [44]), bearing capacity may be expressed as:

$$
\mathrm{q}=\frac{\pi \cdot \mathrm{c}}{1+(\phi-\pi / 2) \cdot \tan \phi}
$$

Starting from the known experimental values for bearing capacity $\mathrm{q}$ and cohesion $\mathrm{c}$, it is possible to calculate the angle of internal friction. From concrete mixtures used in this paper, the friction angle obtained is of $36^{\circ}$. As reported in Reference [39], measured values for friction coefficient varied 
between 0.6 and 0.7 (angles are $31^{\circ}$ and $35^{\circ}$ ). The report is based on Eurocode 2 [45], for concrete series with interface roughness from smooth to rough. Therefore, the value for angle of friction of $36^{\circ}$ is reasonable.

\section{Analysis of Concrete Splitting Tests}

Non-linear analysis of the problem was performed using the incremental finite element method (FEM). The basic equations of the incrementally iterative procedure with the applied algorithm for the integration of constituent equations, used in this paper, are given in Reference [1]. Integration of elastoplastic constitutive relations is done with return mapping algorithm, as described by Simo and Ortiz [46].

The constitutive equations are implemented in the discrete finite element (FE) code, especially developed for the PhD thesis [47]. This code was used for the calculation of the squared or cylindrical sample bearing capacity, exposed to the Indirect Tensile Test. Simulation is done by displacement-controlled method. As presented in the Figure 9a, thanks to double symmetry of the sample, it was possible to perform the numerical analysis for the one quarter, with constant strain triangular elements under plane strain conditions. The dimension of the loading plate was $b / 2=6 \mathrm{~mm}$, and the dimensions of the model are $\mathrm{D} / 2=50 \mathrm{~mm}$. The number of triangular finite elements is 5000 $(50 \times 50 \times 2)$ for modelling one quarter of the concrete block. Boundary conditions are shown on Figure $9 \mathrm{~b}$ (at the left side and at the bottom).
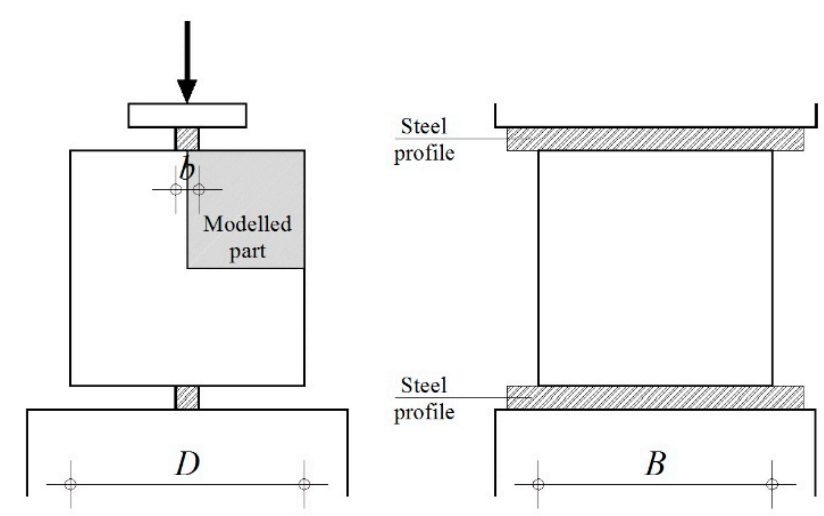

(a)

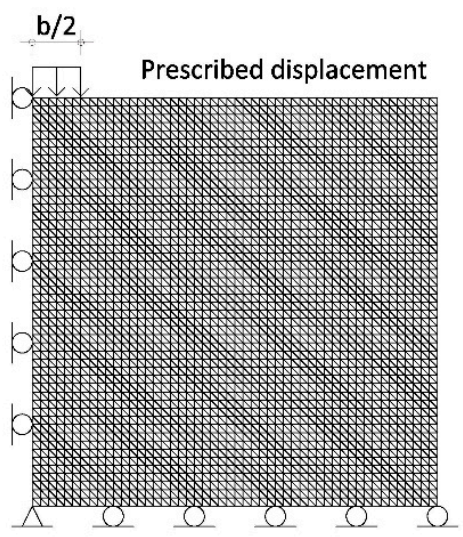

(b)

Figure 9. (a) Schematic drawing showing square test arrangement and (b) model for Finite Element numerical analysis, where the width and height $\mathrm{D} / 2=50 \mathrm{~mm}$, with $\mathrm{b} / 2=6 \mathrm{~mm}$.

Compressive load from the bearing plate was applied to the concrete sample. Compression induced reactive tensile force is perpendicular to the direction of the compressive force. Curves for reactive load versus displacement for concrete series are shown in Figure 10 for selected concrete series. As presented, all curves showed a similar trend: phase 1-initial elastic behaviour, phase 2-plastic deformation followed by sharp bend, phase 3-change in slope until the final failure. Parameters used for simulation are $v=1 / 9$ and $\varphi=36^{\circ}$.

The comparison between bearing capacities, i.e., measured maximum indirect tensile load and load calculated using numerical data from MC model, is shown in the Table 7. Bearing capacities showed a remarkably good correlation with a small difference from 2 to $4 \%$.

Figure 11 shows yielding contours development for concrete series MB-30. The top left figure shows profile under displacement of $0.015 \mathrm{~mm}$. Initially, the plastic zone developed right next to the edge of the bearing plate, as shown in the first profile. For the bearing plate displacement of $0.017 \mathrm{~mm}$, plastic domains and the failure zone increased and became arc like shape, to reach the 
reflected boundary on the left. At the displacement of $0.036 \mathrm{~mm}$ peak load is reached, plastic zone went deeper down. With further displacement, the plastic zone spreads in the elastic region under the bearing plate, load decreased and the end of testing occurred. Observation is similar to schematic Figure $11 \mathrm{c}$, where shear fracture occurs under the bearing plate. Load bearing capacity and fracture of the sample are reached at the same point.

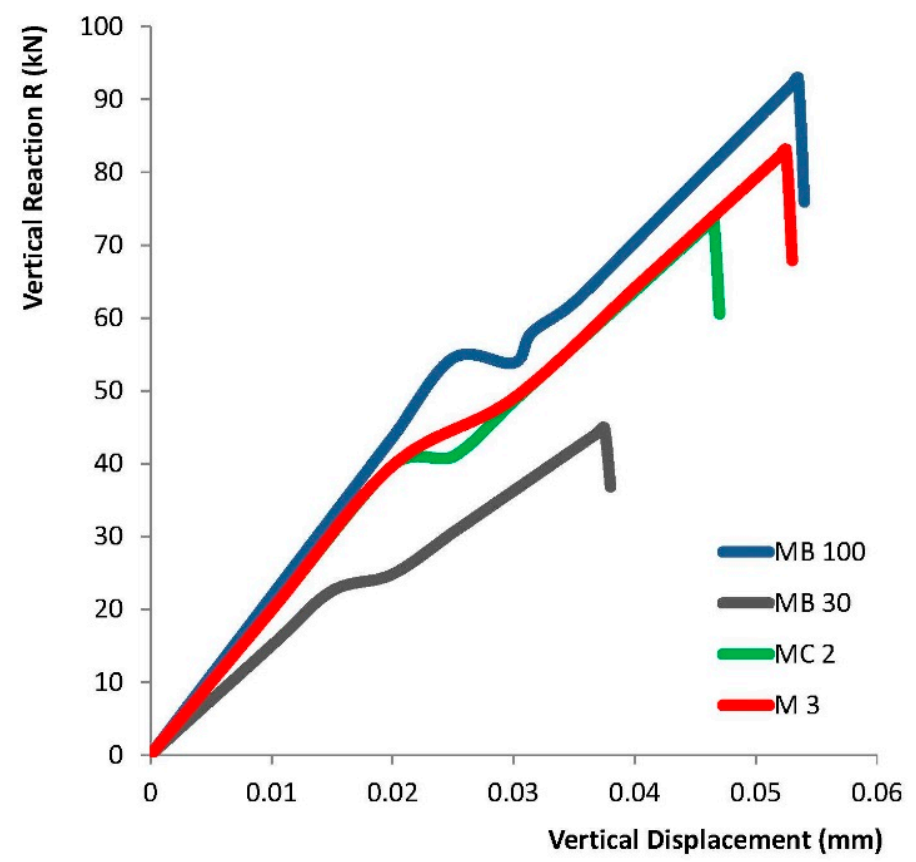

Figure 10. Load-displacement curves for concrete series.

Table 7. Summary of experimental and numerical results for ultimate load for concrete series.

\begin{tabular}{|c|c|c|c|c|c|c|}
\hline \multirow[b]{2}{*}{ Sample Series } & \multicolumn{2}{|c|}{ Experimental } & \multicolumn{3}{|c|}{ Numerical } & \multirow[b]{2}{*}{$\Delta(\%)$} \\
\hline & $P_{\max }(k N)$ & $\sigma_{t}(\mathrm{MPa})$ & $\mathrm{E}(\mathrm{GPa})$ & c (MPa) & $P_{\text {max }}^{*}(k N)$ & \\
\hline MB 30 & 44.0 & 2.8 & 31 & 3.9 & 44.85 & 1.9 \\
\hline MC 2 & 70.7 & 4.5 & 41 & 6.0 & 73.50 & 4.0 \\
\hline M 3 & 80.1 & 5.1 & 43 & 6.8 & 83.03 & 3.7 \\
\hline MB 100 & 89.5 & 5.7 & 45 & 7.6 & 92.85 & 3.8 \\
\hline
\end{tabular}

Pmax-Measured value; $P^{*} \max -$ Calculated value.

For the performed FEM analysis of concrete split cylinder test, Chen [2] used Drucker-Prager plasticity model. It was observed that initial crack started to form at the edge of the loading plate. Following the development of the initial crack, the bearing plate was pushed down into the concrete sample. Consequently, changes in distribution and ratio between horizontal and vertical stresses in their profiles appeared. When the crack reached the reflected boundary, the fracture point was reached. Diagram of the deformations presented in Figure 10 shows similarities with the modes of failure calculated using linear dynamic analysis presented in Reference [48]. According to the linear theory equations, this express the relationship between vertical and horizontal stresses and vertical diameter of the cylinder-the value of the compressive stress is high in the vicinity of the loading point, while the value of the tensile stress is high along the vertical centreline of the cylinder. As a result of the linear dynamic analysis, crack initiation started to develop at the cylinder centre. However, results of the non-linear dynamic analysis, indicated first crack propagation at the point of approximately 0.2. $\mathrm{D}$ ( $\mathrm{D}=$ diameter of the cylinder). A further development of the crack appeared along the vertical centreline, in both directions, toward the top and bottom surfaces. 
The main advantage of the presented FEM model is that it uses only four material parameters in nonlinear material analysis: Young's modulus E, Poisson's ratio $v$, cohesion $\mathrm{c}$ and angle of internal friction, $\varphi$. Load deformation curves obtained with FEM model showed remarkable matching with test results. It confirms that the proposed method is applicable in numerical analysis.

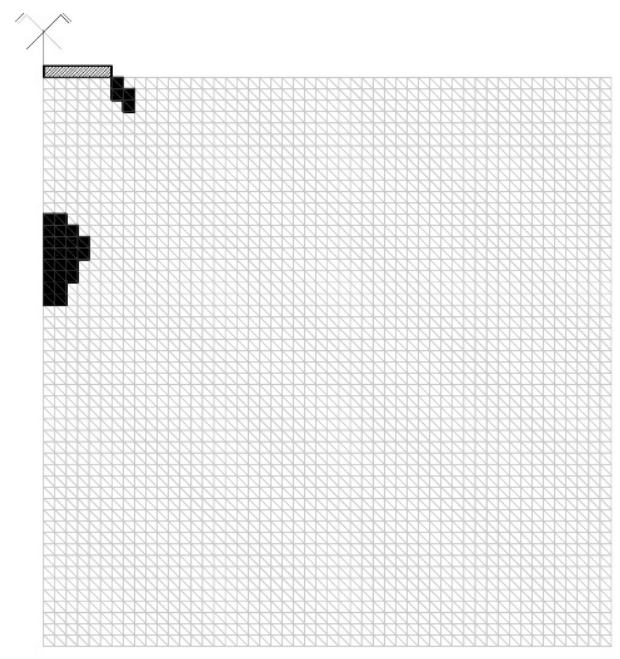

(a)

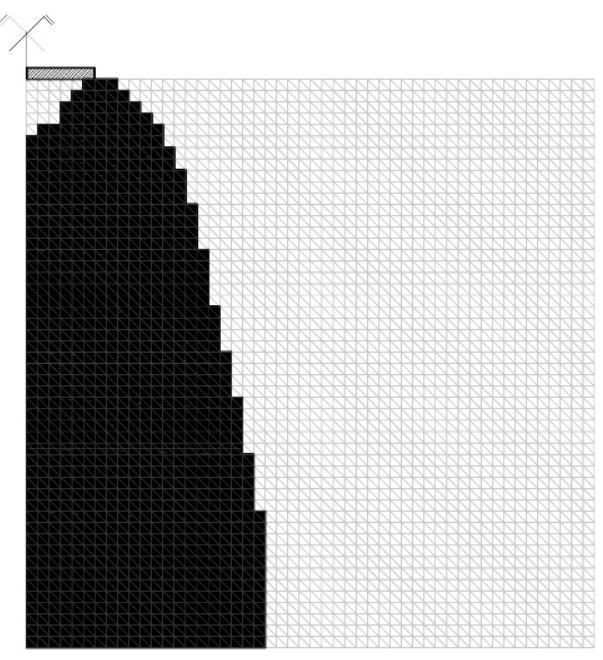

(c)

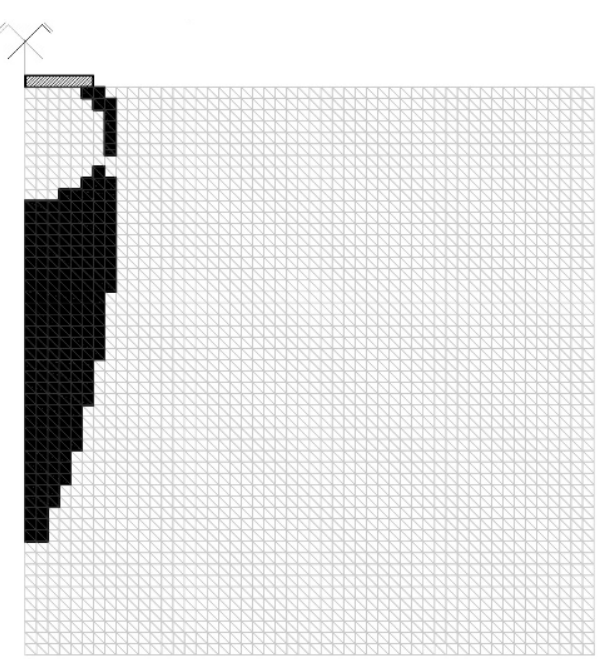

(b)

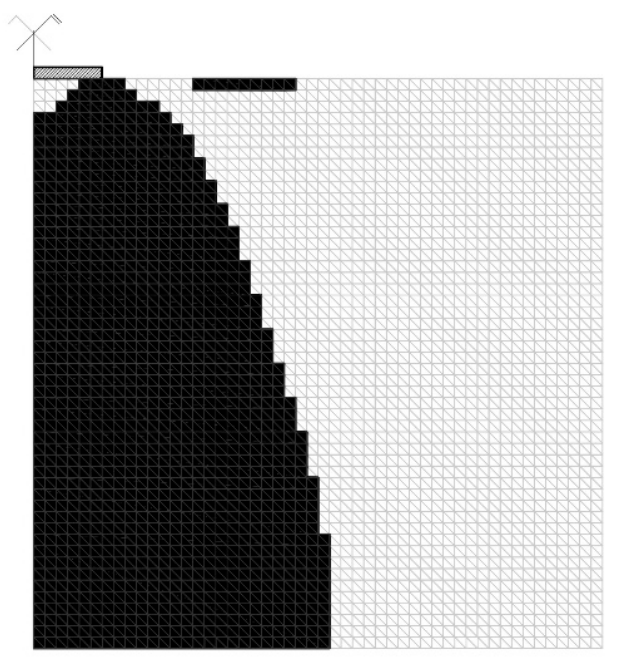

(d)

Figure 11. Spread of yielded zone series MB30. (a) Vertical displacement v $=0.015 \mathrm{~mm}$. (b) Vertical displacement $\mathrm{v}=0.017 \mathrm{~mm}$. (c) Vertical displacement $\mathrm{v}=0.036 \mathrm{~mm}$. (d) Vertical displacement $\mathrm{v}=0.040 \mathrm{~mm}$.

\section{Conclusions}

This paper presents a new method of experimental approach to the cohesion determination from the shear stress axis with tests at pre-set values of the deformation angle. Specially designed moulds are used for testing deformation of material at pre-set low values of the shear angle. Measurements were performed on a series of samples and statistical analysis were applied on experimental results in attempt to average material's deformational behaviour. Experimental cohesion is the common value between indirect tensile test and forced shear test. Starting with the measured values for bearing capacity and cohesion, friction angle is determined. An application of the Mohr-Coulomb model for numerical analysis was performed. Data obtained from the calculations were compared to representative experimental measurements. There was a good fit between experimental data and 
numerical modelling. These results confirm that the proposed procedure, using only four material parameters, is applicable in numerical analysis and modelling of concrete.

Author Contributions: S.L. designed the model, the computational framework and performed the numerical analysis. D.V. designed the concrete mixtures and molds for the experiment. S.L. took the lead in writing the manuscript. Both authors have read and agreed to the published version of the manuscript.

Funding: This research received no external funding.

Acknowledgments: The authors wish to thank Aleksandar Radević from the University of Belgrade for his help with shear test measurements.

Conflicts of Interest: The authors declare no conflict of interest.

\section{References}

1. Potts, D.M.; Zdravkovic, L. Finite Elements Analysis in Geotechnical Engineering-Theory; Thomas Telford Publishing: London, UK, 1999.

2. Chen, W.F. Plasticity in Reinforced Concrete; McGraw Hill: New York, NY, USA, 1982.

3. Chen, A.C.T.; Chen, W.F. Constitutive Relations for Concrete. ASCE J. Eng. Mech. 1975, 101, 465-481.

4. Lubliner, J.; Oliver, J.; Oller, S.; Oñate, E. A plastic-damage model for concrete. Int. J. Solids Struct. 1989, 25, 299-326. [CrossRef]

5. Krajcinovic, D. Continuous Damage Mechanics Revisited: Basic Concepts and Definitions. J. Appl. Mech. 1985, 52, 829-834. [CrossRef]

6. Lubliner, J. Plasticity Theory; Mac Millan: New York, NY, USA, 1990.

7. Vukelic, S. Analysis of Mechanical Deformation of Concrete. Ph.D. Thesis, University of Belgrade, Faculty of Civil Engineering, Belgrade, Serbia, 1981.

8. Hu, H.-T.; Schnobrich, W.C. Constitutive Modeling of Concrete by Using Nonassociated Plasticity. J. Mater. Civ. Eng. 1989, 1, 199-216. [CrossRef]

9. Mehta, P.K.; Monteiro, P.J. Concrete: Structure, Properties and Materials; Prentice Hall: Upper Saddle River, NJ, USA, 1993.

10. Chae, S.R.; Moon, J.; Yoon, S.; Bae, S.; Levitz, P.; Winarski, R.; Monteiro, P.J.M. Advanced Nanoscale Characterization of Cement Based Materials Using X-Ray Synchrotron Radiation: A Review. Int. J. Concr. Struct. Mater. 2013, 7, 95-110. [CrossRef]

11. Daigle, M.; Fratta, D.; Wang, L.B. Ultrasonic and X-ray Tomographic Imaging of Highly Contrasting Inclusions in Concrete Specimens. In Proceedings of the GeoFrontier Conference, Austin, TX, USA, 24-26 January 2005; pp. 1-12.

12. Caliskan, S. Examining Concrete Cores by Non-destructive Techniques. In Proceedings of the 4th Middle East NDT Conference and Exhibition, Manama, Bahrain, 2-5 December 2007.

13. Bazant, Z.P.; Pang, S.D.; Verchovsky, M.; Novak, D.; Pukl, R. Statistical size effect in quasibrittle materials computation and extreme value theory. In Fracture Mechanics of Concrete Structures; Li, V.C., William, K.J., Billington, S.L., Eds.; IA-FraMCoS: Vail, CO, USA, 2004; pp. 189-196.

14. Lowes, L. Finite Element Modeling of Reinforced Concrete Beam Column Bridge Connections. Ph.D. Thesis, UC Berkeley, Berkeley, CA, USA, 1999.

15. Karsan, I.D.; Jirsa, J.O.; Chen, W.F. Behavior of concrete under compressive loadings. J. Struct. Div. ASCE 1969, 95, 2535-2563.

16. Chen, W.F. Limit Analysis and Soil Plasticity; J. Ross Publishing: Fort Lauderdale, FL, USA, 2007; p. 543.

17. Gopalaratnam, V.S.; Shah, S.P. Softening response of plain concrete in direct tension. ACI J. 1985, 82, 311-323.

18. Taquieddin, Z.N. Elasto-plastic and Damage Modeling of Reinforced Concrete. Ph.D. Thesis, Louisiana State University, Baton Rouge, LA, USA, 2008.

19. Hobbs, D.W. The tensile strength of rocks. Int. J. Rock Mech. Min. Sci. 1964, 1, 385-396. [CrossRef]

20. Fan, Q.; Gu, S.C.; Wang, B.N.; Huang, R.B. Two Parameter Parabolic Mohr Strength Criterion Applied to Analyze The Results of the Brazilian Test. Appl. Mech. Mater. 2014, 624, 630-634. [CrossRef]

21. Ma, T.; Peng, N.; Zhu, Z.; Zhang, Q.; Yang, C.; Zhao, J. Brazilian Tensile Strength of Anisotropic Rocks: Review and New Insights. Energies 2018, 11, 304. [CrossRef] 
22. Sivakugan, N.; Das, B.M.; Lovisa, J.; Patra, C.R. Determination of c and w of rocks from indirect tensile strength and uniaxial compression tests. Int. J. Geotech. Eng. 2014, 8, 59-65. [CrossRef]

23. Piratheepan, J.; Gnanendran, C.T.; Arulrajah, A. Determination of c and w from an IDT and unconfined compression testing and numerical analysis. J. Mater. Civ. Eng. 2012, 24, 1153-1163. [CrossRef]

24. Meschke, G. Consideration of aging of shotcrete in the context of a 3D viscoplastic material model. Int. J. Numer. Methods Eng. 1996, 39, 3123-3143. [CrossRef]

25. Altoubat, S.A.; Lange, D.A. Early Age Shrinkage and Creep of Fiber Reinforced Concrete for Airfield Pavement. In Proceedings of the 1997 Airfield Pavement Conference, Seattle, WA, USA, 17-20 August 1997.

26. Galic, M.; Marovic, P.; Nikolic, Ž. Modified Mohr-Coulomb-Rankine material model for concrete. Eng. Comput. 2011, 28, 853-887. [CrossRef]

27. Wu, D.; Wang, Y.; Qiu, Y.; Zhang, J.; Wan, Y.-K. Determination of Mohr-Coulomb Parameters from Nonlinear Strength Criteria for 3D Slopes. Math. Probl. Eng. 2019, 6927654. [CrossRef]

28. Japaridze, L. Stress-deformed state of cylindrical specimens during indirect tensile strength testing. J. Rock Mech. Geotech. Eng. 2015, 7, 509-518. [CrossRef]

29. ASTM. Standard Test Method for Splitting Tensile Strength of Intact Rock Core Specimens; D 3967-08; ASTM International: West Conshohocken, PA, USA, 2008.

30. Japaridze, L. Shear Stresses in the Indirect Test of Tensile Strength of Rocks and other Hard Materials. Bull. Georgian Natl. Acad. Sci. 2016, 10, 45-54.

31. Li, D.; Wong, L.N.Y. The Brazilian Disc Test for Rock Mechanics Applications: Review and New Insights. Rock Mech. Rock Eng. 2012, 46, 269-287. [CrossRef]

32. Kömürlü, E.; Demir, A.D. Determination of Cohesion values of Rock Materials using Double Shear Jaws. Period. Polytech. Civ. Eng. 2018, 62, 881-892. [CrossRef]

33. Majstorovic, J.; Andelkovic, V.; Dimitrijevic, B.; Savkovic, S. Laboratory testing of shear parameters through rock mass and along discontinuities. Undergr. Min. Eng. 2012, 21, 135-142.

34. Institute for Standardization of Yugoslavia, JUS B.B7.130/1988, Rock Mechanics. Testing of physical and mechanical properties. In Method for Determining Limiting Shear Strength; Collection of Yugoslavian Standards for Building Constructions, Book 6-1 Geotechnic and Foundations; Faculty of Civil Engineering: Belgrade, Serbia, 1995; pp. 173-175. ISBN 86-80049-20-4.

35. Lelovic, S.; Vasovic, D.; Stojic, D. Determination of the Mohr-Coulomb Material Parameters for Concrete under Indirect Tensile Test. Tech. Gaz. 2019, 26, 412-419.

36. O'Neil, E.; Neeley, B.; Cargile, J.D. Tensile Properties of Very-High-Strength Concrete for Penetration-Resistant Structures. Shock Vib. 1999, 6, 237-245. [CrossRef]

37. Carrasquillo, R.L.; Nilson, A.H.; Slate, F.O. Properties of high strength concrete subjected to short-term load. ACI J. 1981, 78, 171-178.

38. Oluokun, F. Prediction of Concrete Tensile Strength from its Compressive Strength: An Evaluation of Existing Relations for Normal Weight Concrete. ACI Mater. J. 1991, 88, 302-309.

39. Building code requirements for structural plain concrete (ACI 318.1-83) and commentary. Int. J. Cem. Compos. Lightweight Concr. 1985, 7, 60. [CrossRef]

40. Bae, B.-I.; Choi, H.-K.; Choi, C.-S. Correlation Between Tensile Strength and Compressive Strength of Ultra High Strength Concrete Reinforced with Steel Fiber. J. Korea Concr. Inst. 2015, 27, 253-263. [CrossRef]

41. Mohamad, M.; Ibrahim, I.; Abdullah, R.; Rahman, A.A.; Kueh, A.; Usman, J. Friction and cohesion coefficients of composite concrete-to-concrete bond. Cem. Concr. Compos. 2015, 56, 1-14. [CrossRef]

42. Chen, Y.; Visintin, P.; Oehlers, D.J. Concrete Shear-Friction Material Properties: Derivation from Actively Confined Compression Cylinder Tests. Adv. Struct. Eng. 2015, 18, 1173-1185. [CrossRef]

43. Citovich, N.A. Soil Mechanics, 4th ed.; Student Press: Moscow, Russia, 1979; p. 341.

44. Nielsen, M.P.; Hoang, L.C. Limit Analysis and Concrete Plasticity, 3rd ed.; CRC Press: Boca Raton, FL, USA, 2010; p. 176.

45. EN 1992-1-1 (2004) (English): Eurocode 2: Design of concrete structures-Part 1-1: General Rules and Rules for Buildings; European Committee for Standardization, December 2004; Available online: https://www.phd.eng. br/wp-content/uploads/2015/12/en.1992.1.1.2004.pdf (accessed on 9 September 2020). 
46. Ortiz, M.; Simo, J.D. An analysis of a new class of integration algorithms for elastoplastic constitutive relations. Int. J. Numer. Methods Eng. 1986, 23, 353-366. [CrossRef]

47. Lelovic, S. Constitutive Equations for Sand and Their Application in Numerical Analysis of Strip Foundation Behavior. Ph.D. Thesis, University of Belgrade, Beograd, Serbia, 2013.

48. Tedesco, J.W. Numerical Analysis of Dynamic Splitting Tensile and Direct Tension Tests; Air Force Report (ESL-TR-89-45) Air Force Engineering, Tyndall AFB FL 32403; National Technical Information Service: Springfield, VA, USA, 1990.

(C) 2020 by the authors. Licensee MDPI, Basel, Switzerland. This article is an open access article distributed under the terms and conditions of the Creative Commons Attribution (CC BY) license (http://creativecommons.org/licenses/by/4.0/). 